\title{
A PRÁTICA DA LEITURA LITERÁRIA: reflexão-ação-transformação por meio de grupo de diálogo coletivo
}

\author{
Elaine Rodrigues Nichio' \\ Juracy Machado Pacífico²
}

\section{RESUMO}

Este artigo é resultado da dissertação de mestrado intitulada "Os desafios da leitura literária no ensino médio: (re)descobrindo caminhos". Na investigação, buscou-se identificar as principais causas que levaram os alunos do segundo ano do curso Técnico em Agropecuária do IFRO - campus Colorado do Oeste/RO a apresentar rejeição pela leitura literária para, assim, intervir com práticas pedagógicas que contribuam para a formação do leitor. Metodologicamente, optou-se pela abordagem qualitativa e pela pesquisa-ação, na medida em que esta se constitui como ação reflexiva que pode levar à transformação da realidade. Atuou-se dinamicamente nos problemas por meio de um trabalho em conjunto com os alunos participantes: em suas ações, eles refletiram e avaliaram todo o processo de transformação da situação. Como fonte de dados, foram utilizados a pesquisa bibliográfica, o diário de campo e o diálogo coletivo, que foi caracterizado por momentos de discussão e de intervenção com os alunos participantes. Dentre os resultados, a falta de tempo e as dificuldades de compreensão do texto literário aparecem como os principais motivos para que os alunos se distanciassem da leitura literária. O diálogo se apresentou como um caminho para a reflexão e para a transformação das práticas pedagógicas. O principal produto da intervenção foram as sequências didáticas, elaboradas juntamente com os alunos participantes com base na problemática levantada nas discussões do grupo Diálogo Coletivo. Conclui-se que a referida pesquisa possibilitou uma abordagem dialógica, na qual as relações entre pesquisadora e alunos participantes se entrecruzaram e se fortaleceram, e, ao mesmo tempo, que o diálogo é uma ponte para a resolução dos problemas e para o crescimento humano.

Palavras-chave: Leitura Literária. Práticas Pedagógicas no Ensino Médio. Ensino de Literatura. Pesquisa-Ação.

\section{THE PRACTICE OF LITERARY READING: reflection-action-transformation through a collective dialogue group}

\begin{abstract}
This article is the result of the master's thesis entitled "The challenges of literary reading in high school: (re) discovering paths. In the investigation, we sought to identify the main causes that led the students of the second year of the Technical course in Agriculture at the IFRO campus Colorado do Oeste / RO to present rejection for literary reading in order to intervene with pedagogical practices that contribute to the training of the reader. Methodologically,

'Mestre em Educação Escolar (UNIR). Professora de Língua Portuguesa e Literatura do Instituto Federal de Educação, Ciência e Tecnologia de Rondônia (IFRO). ORCID: https://orcid.org/0000-0002-3719-2793 E-mail: elaine.rodrigues11@hotmail.com

2Doutora em Educação Escolar (UNESP). Professora da Graduação e Pós-Graduação

Escolar, Mestrado e Doutorado Profissional da Universidade Federal de Rondônia. ORCID:

http://orcid.org/0000-0003-0486-874X E-mail: juracypacifico@unir.br
\end{abstract}

Revista Exitus, Santarém/PA, Vol. 10, p. 01-30, e020041, 2020. 
we opted for the qualitative approach and action research, insofar as it constitutes a reflexive action that can lead to the transformation of reality. The problems were acted on dynamically by working together with the participating students: in their actions, they reflected and evaluated the entire process of transforming the situation. As a source of data, bibliographic research, field diary and collective dialogue were used, which was characterized by moments of discussion and intervention with participating students. Among the results, lack of time and difficulties in understanding the literary text appear as the main reasons for students to distance themselves from literary reading. The dialogue presented itself as a path for reflection and for the transformation of pedagogical practices. The main product of the intervention was the didactic sequences, developed together with the participating students based on the problem raised in the discussions of the Collective Dialogue group. It is concluded that the referred research made possible a dialogical approach, in which the relations between researcher and participating students were intertwined and strengthened, and, at the same time, that the dialogue is a bridge for the resolution of problems and for human growth.

Keywords: Literary Reading. Pedagogical Practices in High School. Literature teaching. Action Research.

\section{LA PRÁCTICA DE LA LECTURA LITERARIA: reflexión-acción-transformación a través del grupo de diálogo colectivo}

\section{RESUMEN}

Este artículo es el resultado de la tesis de maestría titulada "Los desafíos de la lectura literaria en la escuela secundaria: (re) descubrir caminos. En la investigación, buscamos identificar las causas principales que llevaron a los estudiantes del segundo año del curso Técnico en Agricultura en el IFRO - campus Colorado do Oeste / RO a presentar el rechazo a la lectura literaria para intervenir con prácticas pedagógicas que contribuyen a la capacitación. Del lector. Metodológicamente, optamos por el enfoque cualitativo y la investigación-acción, ya que esto constituye una acción reflexiva que puede conducir a la transformación de la realidad. Los problemas se resolvieron dinámicamente trabajando junto con los estudiantes participantes: en sus acciones, reflejaron y evaluaron todo el proceso de transformación de la situación. Como fuente de datos, se utilizó la investigación bibliográfica, el diario de campo y el diálogo colectivo, que se caracterizó por momentos de discusión e intervención con los estudiantes participantes. Entre los resultados, la falta de tiempo y las dificultades para comprender el texto literario aparecen como las principales razones por las cuales los estudiantes se distancian de la lectura literaria. El diálogo se presentó como un camino para la reflexión y para la transformación de las prácticas pedagógicas. El producto principal de la intervención fueron las secuencias didácticas, desarrolladas junto con los estudiantes participantes en función del problema planteado en las discusiones del grupo de Diálogo Colectivo. Se concluye que la investigación referida hizo posible un enfoque dialógico, en el que las relaciones entre el investigador y los estudiantes participantes se entrelazaron y fortalecieron, y, al mismo tiempo, que el diálogo es un puente para la resolución de problemas y el crecimiento humano.

Palabras clave: Lectura literaria. Prácticas pedagógicas en la escuela secundaria. Enseñanza de literatura. Investigación de acción.

\section{INTRODUÇÃO}

Revista Exitus, Santarém/PA, Vol. 10, p. 01-30, e020041, 2020. 
O desenvolvimento da pesquisa sugere um repensar sobre o ensino da literatura, cujo estudo é de suma importância para a formação social do ser humano. Observamos que, ao chegar ao ensino médio, grande parte dos alunos nunca teve um contato mais próximo com o texto literário, o que pode ser uma das explicações para a falta de interesse pela disciplina. Esse foi o tema da pesquisa.

Para delimitar o grupo de participantes da pesquisa, optamos por uma turma de 30 alunos do segundo ano do curso Técnico em Agropecuária do IFRO - campus Colorado do Oeste/ RO. O objetivo foi encontrar respostas para a seguinte questão: quais são as principais causas da falta de interesse pela leitura literária por parte dos alunos do segundo ano do ensino médio?

Caracterizando-a como uma pesquisa-ação, propusemos uma intervenção no que entendemos ser uma situação conflitante e elaboramos uma proposta de prática pedagógica de trato diferenciado com a leitura literária. Assim, concebendo a leitura como instrumento de comunicação e de interação social e também como uma fonte de acesso aos diferentes saberes culturais, procuramos contribuir significativamente para a formação do leitor literário.

Entendemos que a pesquisa-ação possibilita essa formação, já que, é "um instrumento para compreender a prática, avaliá-la e questioná-la, exigindo, assim, formas de ação e tomada consciente de decisões (ABDALLA, 2005, p. 386)". Todos os envolvidos têm participação ativa na construção das propostas, produzindo conhecimento sobre a realidade estudada.

Para a coleta de dados, utilizamos a análise bibliográfica (LUNA, 2002), o diário de campo (LUDKE; ANDRÉ, 2017) e o diálogo coletivo, inspirado na metodologia do grupo focal (GATTI, 2005).

Os procedimentos de pesquisa obedeceram aos Critérios da Ética em Pesquisa com Seres Humanos, conforme Resolução no 510 de 07 de abril de 2016 - Conselho Nacional de Saúde CONSEP, tendo sido aprovados pelo Parecer de número 2.847.385. 
De nossa perspectiva, é pela motivação do ainda não descoberto que se vai ao encontro de novos caminhos ou (re) descobrimos os antigos, uma vez que estes nunca serão os mesmos. Oliveira, Velanga e Pacífico (2016, p. 165) nos lembram que "Ler é ato libertador. Quanto mais lemos mais temos vontade e condições de liberdade." A busca se justifica: os agentes, professor e alunos, saem de sua zona de conforto e, juntos, podem encontrar meios para a formação de leitores literários.

\section{Ressignificando a prática do ensino da literatura: grupo Diálogo Coletivo}

Nesse tópico, descrevemos a formação de um grupo denominado "Diálogo Coletivo", bem como as ações ou experiências vivenciadas por seus integrantes. Apresentamos os resultados das discussões coletivas sobre a temática, dentre os quais as ações propostas para minimizar o problema encontrado nas discussões. Na análise, cada aluno participante é visto em seus anseios, seus medos, suas expectativas e, acima de tudo, como um sujeito capaz de modificar positivamente seu meio.

Os dados coletados estão organizados com base nos temas relacionados a cada ação desenvolvida.

QUADRO 1- Síntese do itinerário percorrido na pesquisa-ação

\begin{tabular}{|c|l|}
\hline $\begin{array}{c}\text { Formação do } \\
\text { grupo "Diálogo } \\
\text { Coletivo" }\end{array}$ & $\begin{array}{l}\text { Esta análise aponta a importância de o professor } \\
\text { pesquisador ser reflexivo a respeito de sua prática. Dessa } \\
\text { forma, por meio do convite para a participação no } \\
\text { Grupo "Diálogo Coletivo", foi criado um espaço para a } \\
\text { formação de conhecimento e para o posicionamento } \\
\text { crítico. }\end{array}$ \\
\hline & $\begin{array}{l}\text { Primeiro encontro: Diálogo sobre o que é literatura. } \\
\text { Reflexão sobre a importância da literatura. }\end{array}$ \\
$\begin{array}{c}\text { Encontros do } \\
\text { Gupo "Diálogo } \\
\text { Coletivo" }\end{array}$ & $\begin{array}{l}\text { Segundo encontro: Diálogo sobre a base familiar de } \\
\text { incentivo à leitura. Resgate da infância. }\end{array}$ \\
& $\begin{array}{l}\text { Terceiro encontro - Diálogo sobre as preferências de } \\
\text { leitura. Reflexão sobre os motivos que nos levam a fazer } \\
\text { determinadas escolhas. }\end{array}$ \\
\hline
\end{tabular}




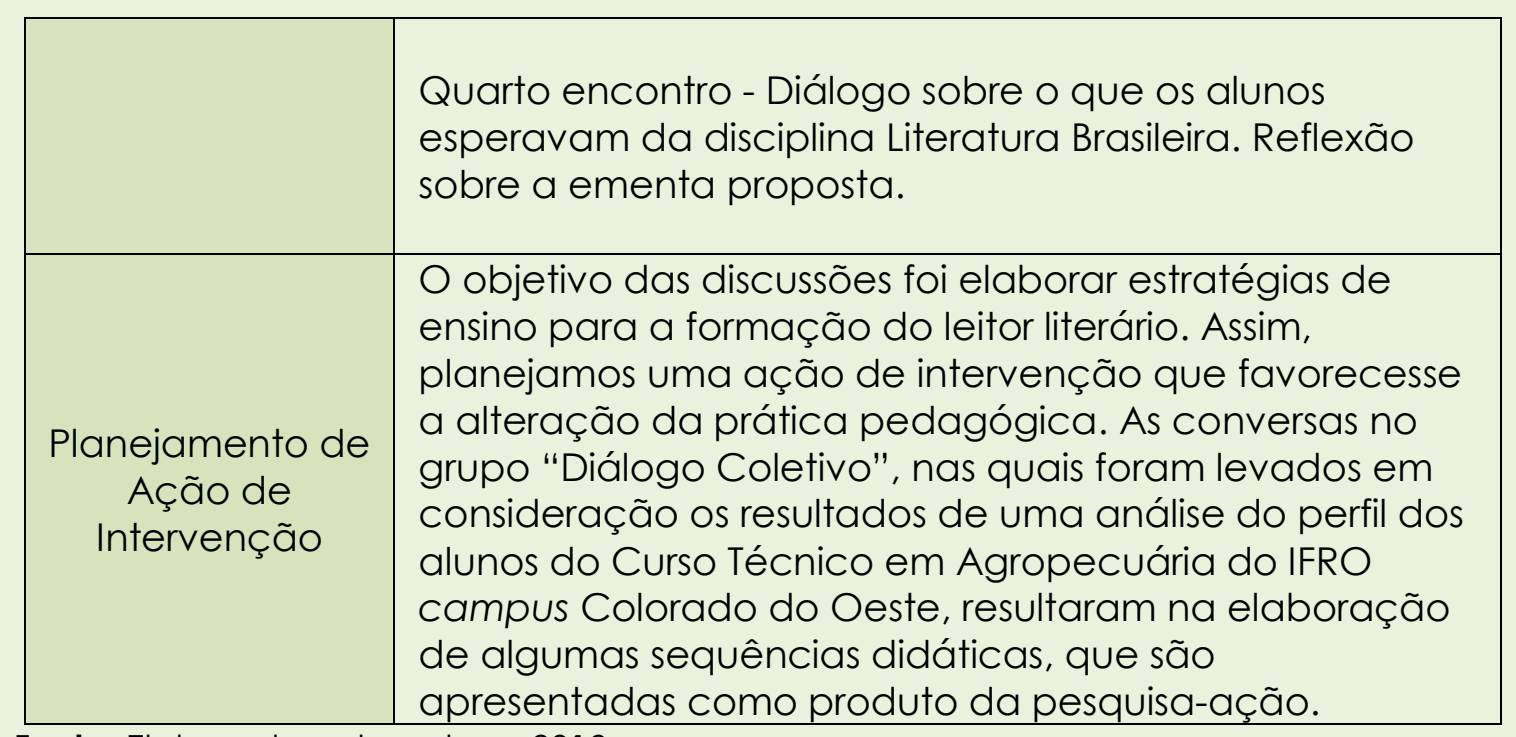

Fonte: Elaborado pela autora, 2018.

Discutiremos, nos próximos subitens, cada uma das etapas desenvolvidas na pesquisa-ação, sinteticamente apresentadas no quadro 1.

\section{Formação do grupo "Diálogo Coletivo": o professor pesquisador e a reflexão sobre sua prática}

A orientação dialógica é naturalmente um fenômeno próprio a todo discurso. Trata-se da orientação natural de qualquer discurso vivo. Em todos os seus caminhos até o objeto, em todas as direções, o discurso se encontra com o discurso de outrem e não pode deixar de participar, com ele, de uma interação viva e tensa. Apenas o Adão mítico que chegou com a primeira palavra num mundo virgem, ainda não desacreditado, somente este Adão podia realmente evitar por completo esta mútua orientação dialógica do discurso alheio para o objeto. Para o discurso humano, concreto e histórico, isso não é possível: só em certa medida e convencionalmente é que pode dela se afastar (BAKHTIN, 1988, p. 88).

A organização do grupo "Diálogo Coletivo" baseia-se na perspectiva dialógica bakhtiniana (1988) e nos círculos de cultura de Freire (2007).

Bakhtin, prezando as relações estabelecidas entre o sujeito e o seu meio, entende que um depende incondicionalmente do outro para lhe dizer sobre si o que ele, de seu lugar, não pode ver e, assim, reciprocamente. Isso implica que, ao expor suas ideias, um não pode desprezar as do outro, mas precisa se colocar na posição de sujeito incompleto que pode se fazer e 
refazer por meio de um movimento dialógico. Com base nessa perspectiva, em vez de dividir a sala em pequenos grupos, optamos por criar oportunidades para um diálogo aberto.

Já Freire, também propunha relações em equipe para encontrar caminhos para solucionar os problemas detectados. Primando pelo bem coletivo e pelo crescimento social, tomava individualmente a responsabilidade pelo crescimento do coletivo.

Assim, as duas bases para a formação do grupo Diálogo Coletivo foram as da interação discursiva e da criação de um campo democrático e autônomo. Entendemos que, com base no respeito e no compromisso individual com o social, os problemas podem ser evidenciados e as soluções, encontradas coletivamente.

Em nosso caso, a pesquisa nasceu do anseio por encontrar caminhos para a formação do leitor literário. Do mesmo modo que Figueira (2018, p. 325), também nos questionamos sobre "Quais recursos utilizar para construir o gosto pela leitura em um contexto avesso ao livro"? Consideramos que se trata de um repensar sobre a prática pedagógica, de um exercício reflexivo sobre a ação e a reflexão como constituintes da práxis (FREIRE, 1979) e, mais do que isso, sobre uma prática intelectual crítica (CONTRERAS, 2002).

O grupo foi composto por trinta alunos de uma turma do segundo ano do Curso Técnico em Agropecuária do IFRO, campus Colorado do Oeste. Ressaltamos que nem todos se fizeram presente sem alguns encontros, mas tais ausências não foram consideradas como desistência, pois os motivos eram típicos da turma: alguns tinham dificuldade para chegar à escola, o que acarretava faltas e atrasos. O nome do grupo é Diálogo Coletivo em razão da conversa aberta estabelecida entre todos os integrantes da turma. Todos juntos, em círculo, em um espaço para discutir o ensino da disciplina, participaram da busca de meios para, com base no perfil dos alunos e do curso, aproximar o aluno da Literatura, considerando que esta "[...] propicia a estudantes um lugar especial em si mesmo. Lugar que a biologia não pode chegar, que os elementos da gramática são incapazes de acessar, lugar 
íntimo e valioso do ser humano [...]: a alma humana." (FONSECA; PACÍFICO; NICHIO; SOUZA, 2019, p. 115-116). Por meio do diálogo aberto, foram levantados dados das principais causas da repulsa pela leitura literária, o que resultou no planejamento de uma ação de intervenção, composta de sequências didáticas que, primando pela formação do leitor (COSSON, 2006) e considerando o aluno como receptor ativo e dinâmico diante o texto (JAUSS, 1979), apresentassem novas possibilidades para o ensino da Literatura.

O primeiro passo para a formação do grupo dependia do aceite dos alunos para participar no projeto de pesquisa e, por isso, o convite foi enviado para o e-mail da turma. No dia marcado, todos se fizeram presentes na própria sala da classe e foi acordado que os encontros seriam na quartafeira do período vespertino, pois, durante o ano de 2018, esse horário já era destinado para atividades extraclasse. Como não era distribuída nenhuma aula para esse período, cada professor podia marcar antecipadamente as atividades com os alunos.

Nesse encontro, explicamos os objetivos do projeto e todos os termos de consentimento. Consideramos, incialmente, "[...] que qualquer intervenção deve partir do que o educando conhece e reconhece para assim, ampliar-se até o que ele necessita." (RODRIGUES; MATTIA; SILVA, p. 35, 2017). Os alunos puderam tirar suas dúvidas e perceberam que, diferentemente dos outros momentos, participariam ativamente na construção de uma proposta de ensino, ou seja, teriam voz. "O educador que escuta aprende a difícil lição de transformar o seu discurso, às vezes necessário, ao aluno, em uma fala com ele" (FREIRE, 1997, p.71). Esse momento de escuta sensível foi imprescindível para fortalecer as relações entre os membros da classe, estabelecer mais confiança entre alunos e professor e intervir na prática por meio de um discurso democrático e um diálogo coerente entre as partes. "A escuta sensível reconhece a aceitação incondicional do outro. Ela não julga, não mede, não compara. [...]" (BARBIER, 2004, p. 94). 
É fato que a correria do cotidiano escolar impede que muitos professores ouçam seus alunos e que a preocupação em dar conta de todos os conteúdos da matriz curricular não favorece a fantástica oportunidade de viver uma experiência significativa.

\begin{abstract}
A experiência, a possibilidade de que algo nos aconteça ou nos toque, requer um gesto de interrupção, um gesto que é quase impossível nos tempos que correm: requer parar para pensar, parar para olhar, parar para escutar, pensar mais devagar, olhar mais devagar, e escutar mais devagar; parar para sentir, sentir mais devagar, demorar-se nos detalhes, suspender a opinião, suspender o juízo, suspender a vontade, suspender o automatismo da ação, cultivar a atenção e a delicadeza, abrir os olhos e os ouvidos, falar sobre o que nos acontece, aprender a lentidão, escutar os outros, cultivar a arte do encontro, calar muito, ter paciência e dar-se tempo e espaço. (LARROSA, 1999, p. 21)
\end{abstract}

Os alunos da turma participante da pesquisa apresentavam muitos problemas. Um colega não respeitava a fala do outro, os diálogos instituídos eram carregados de agressão, eles não se olhavam dentro dos olhos. Com a criação do grupo Diálogo Coletivo, visávamos levá-los a experimentar o novo por meio do exercício do diálogo, levá-los a entender que: "A palavra é uma espécie de ponte lançada entre mim e os outros. Se ela se apoia sobre mim numa extremidade, na outra apoia-se sobre o meu interlocutor" (BAKHTIN, 1988, p.115). Além disso, eles poderiam perceber, na interação, na conversa, uma forma de crescimento mútuo e de transformação social, de saber ouvir e falar no momento certo.

A primeira virtude do diálogo consiste no respeito aos educandos, não somente enquanto indivíduos, mas também enquanto expressões de uma prática social. Não se trata do espontaneísmo, que deixa os estudantes entregues a si próprios. O espontaneísmo, afirma ele, só ajudou até hoje à direita. A presença do educador não é apenas uma sombra da presença dos educandos, pois não se trata de negar a autoridade que o educador tem e representa. (GADOTTI, 1996, p.84). 
O fato de eles se perceberem capazes de transformar uma situação, de se considerarem relevantes, autônomos no sentido de construírem seus conhecimentos (FREIRE, 1997), foi importante para que a turma aceitasse unanimemente o projeto de pesquisa. Por meio do diálogo, foi possível questionar algumas coisas que não estavam indo bem na disciplina e, com base nisso, criar e recriar meios para solucionar o problema.

Entendemos que é por meio do processo de reflexão sobre a ação que o conhecimento pedagógico se constrói, compondo-se de atividades pré-planejadas para posterior avaliação (ELLIOTT, 1998). Assim, a reflexão foi o que impulsionou todas as discussões, sendo entendida, não como um ato isolado, mas como o ponto de partida para ações modificadoras.

[...] Através da reflexão em ação os problemas são construídos e estabelecidos a partir de fenômenos encontrados em sala de aula. É um processo que une e integra "sabedoria, conhecimento implícito, planos, técnicas, ideias e justificação, todos radicados na experiência". (ELLIOTT, 1998, p. 141).

Nesse momento, buscamos uma prática que, além de ser reflexiva, seria intelectual, crítica (CONTRERAS, 2002). Por isso, deixamos claro que precisamos ir além de uma mudança na prática individual em sala de aula, que o ensino não é uma prática constituída somente pelo professor, mas que cada aluno tem participação nessa construção e tem compromisso com a sociedade.

A sala de aula foi o laboratório de análise para a descoberta dos problemas: "não posso conceber um professor que não se questione sobre as razões subjacentes às suas decisões [...] que não faça dos seus planos de aulas meras hipóteses de trabalho a confirmar ou a infirmar no laboratório que é a sala de aula" (ALARCÃO, 2001, p.25).

Buscamos levantar, por meio dos diálogos no grupo, as principais causas do problema e o que poderia ser feito para minimizá-las. Todas as questões lançadas no grupo levavam à reflexão e a uma chamada para a mudança. Explicamos que a reflexão significa não apenas pensar sobre a 
situação, mas analisá-la criticamente, pensar no motivo de sua existência, em suas consequências e nos possíveis impactos na sociedade e, a partir disso, pensar em como se pode agir. Examinar com senso crítico e de forma sistemática a própria prática passa a ser uma atividade investigativa (STENHOUSE, 1984).

Quando pensamos na criação de um grupo na sala de aula para que pudéssemos alcançar os objetivos da pesquisa, preferimos não dividir a turma e optamos por compor um grande grupo, unindo todos os alunos da sala, para que as diferenças fossem respeitadas, para que todos pudessem falar e ser ouvidos de forma autônoma e democrática.

Os alunos sentiram-se motivados ao perceber seu grande valor na pesquisa, ao perceber que o professor nem sempre vem com tudo pronto e pode, juntamente com eles, experimentar novos caminhos. Assim, todos podem construir juntos, criar e recriar, aprender um com o outro e compreender que assim se constrói o conhecimento.

[...] O desenvolvimento do professor pressupõe, assim, um contexto prático no qual os professores são livres para experimentar. Sendo a pesquisa-ação educacional vista como um processo de experimentação curricular inovador, faz pouco sentido falar em desenvolvimento de professores como pesquisadores-ação em contextos nos quais eles não podem livremente experimentar com suas práticas. (ELLIOTT, 1998, p. 143).

O professor não se faz sozinho, nem o aluno se faz sozinho, um precisa do outro. A docência e a discência são indissociáveis (FREIRE, 1997). É nessa relação de completude que o conhecimento foi sendo construído, por meio do diálogo aberto que constituiu o grupo Diálogo Coletivo.

Nos próximos itens, iremos narrar o desenvolvimento dos quatro encontros do grupo Diálogo Coletivo e mostrar sua importância para a reflexão-ação e para a transformação de problemas vertentes na prática da leitura literária no cotidiano da sala de aula. 
Primeiro encontro do grupo "Diálogo Coletivo"

Leite, leitura letras, literatura, tudo o que passa, tudo o que dura tudo o que duramente passa tudo o que passageiramente dura tudo, tudo, tudo não passa de caricatura de você, minha amargura de ver que viver não tem cura (LEMNSKI, 1996, p. 26) Após a apresentação do projeto, marcamos a data do primeiro encontro, que ocorreria logo na semana seguinte, aproveitando assim a manifestação positiva e a empolgação da turma. Em uma quarta-feira, 12 de setembro, reunimo-nos em uma sala pré-preparada, com todas as cadeiras formando um grande círculo. Aos poucos os alunos foram chegando e, no horário combinado, 14horas, todos os trinta alunos estavam presentes.

Depois das boas-vindas, manifestamo-nos novamente sobre a importância de cada um na pesquisa. Após esse primeiro momento, iniciamos uma discussão sobre o que é literatura e refletimos sobre a importância do texto literário.

Diante do primeiro questionamento, "O que entendem por literatura?", todos mudaram de fisionomia, mostrando-se preocupados em proferir uma resposta que poderia ser julgada correta ou errada. Afirmamos que seria importante que eles fossem autênticos e que falar de forma espontânea nos ajudaria a alcançar nosso objetivo. 
Assim, obtivemos o resultado descrito no gráfico abaixo:

GRÁFICO 1- A compreensão dos alunos participantes sobre o que é literatura

\section{0 que os alunos entendem por literatura?}

- Compreendem a literatura como um estudo de obras de grandes autores - os clássicos.(20 alunos)

- Entendem a literatura como o estudo de textos em geral. (8 alunos)

- Concebem a literatura como uma forma de manifestação humana em um dado período da história.(2 alunos)

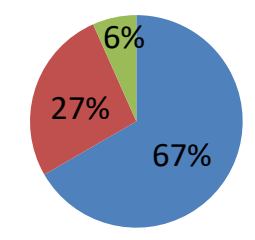

Fonte: Registros levantados no Grupo Diálogo Coletivo em 12 de setembro de 2018.

Fica evidente que a literatura estava sendo entendida pelo grupo de alunos marcado em azul do Gráfico 1 como a reunião de obras de renomados autores. É dessa perspectiva que uma aluna afirma que a literatura seria uma composição "daqueles livros chatos e entediantes" (Aluna A4). Essa fala foi confirmada por todos os vinte alunos pertencentes ao subgrupo que entendia literatura como a reunião de obras de renomados autores.

Entendemos que, para refletir sobre a dificuldade na definição de literatura, um primeiro fator a ser considerado são as tantas mudanças no emprego do termo ao longo da história. Em razão disso, entendemos que não é tão fácil defini-la.

A não compreensão da importância da literatura e também de suas especificidades pode ser explicada pelo fato de que muitos a consideram como um saber desnecessário (COSSON, 2006).

De nossa perspectiva, o fato de o aluno chegar ao ensino médio sem entender a importância da literatura significa que faltou quem lhe trouxesse 
esse esclarecimento, significa que não foram tocados, não tiveram experiência com a literatura (LARROSA, 2002).

Por isso, definimos que outro passo no diálogo seria o da reflexão sobre a relevância da literatura. Para tanto, partimos do conceito que os alunos tinham da literatura como um conjunto de obras, conforme apontou a maioria deles, e consideramos necessário distingui-lo do estereótipo contido na fala dos alunos de que ela estaria fora do alcance das pessoas por causa da linguagem "difícil", que a tornava "chata". Procuramos, assim, mostrar a necessidade de se perceber o texto literário por meio das relações estabelecidas com a linguagem.

Entendemos que, por meio da linguagem, a literatura é um objeto que leva o leitor a interagir com o criador. Cabe ao leitor atribuir sentido à obra. "Uma interpretação que ignorasse esta experiência estética primeira seria própria da presunção do filólogo que cultivasse o engano de supor que o texto fora feito não para o leitor, mas sim, especialmente, para ser interpretado". (JAUSS, 1979, p.45). Para Jauss, a interação das experiências compartilhadas entre leitor e autor, promovendo uma multiplicidade de sentidos, é essencial para que aconteça a fruição estética e o texto se torne vivo.

A multiplicidade de sentidos ocorre não apenas porque o texto literário desperta novos sentidos a cada novo leitor, mas também porque, a cada nova leitura, suscita novas significações no mesmo leitor. É assim que se evidencia a "poética" e a "expressão criativa" do autor.

Nosso ponto de partida foi a compreensão de que a literatura é um trabalho de linguagem e uma forma particular de expressão artística. Para permear nosso diálogo, propusemos a seguinte reflexão:

"Na escola, a leitura literária tem a função de nos ajudar a ler melhor, não apenas porque possibilita a criação do hábito de leitura ou porque seja prazerosa, mas sim, e sobretudo, porque nos fornece, como nenhum outro tipo de leitura faz, os instrumentos necessários para conhecer e articular com proficiência o mundo feito linguagem" (COSSON, 2006, p.30). 
Depois do tempo combinado para leitura e reflexão, três alunos expuseram seu entendimento do texto. Para os dois primeiros, a leitura vai além do simples ato de ler, é preciso refletir profundamente sobre o que se está lendo. Para a outra aluna, "Cabe à escola ensinar literatura e quem mais lê possui mais facilidade na leitura e escrita".

Observamos que, de certa forma, as falas dos alunos estão coerentes entre si, especialmente a respeito do importante papel da leitura literária na escola: esta deve ajudar a ler com autonomia, a criar o hábito da leitura, a dominar o mundo da linguagem.

Nosso primeiro encontro foi encerrado com a citação acima. Assim, pudemos refletir sobre a literatura como algo que só nos faz bem, que agrega e que também nos transporta a outros universos. Os alunos sentiramse bem descontraídos para dialogar a respeito da citação. O aluno A8 disse: "O que eu mais gosto nos livros que leio é poder me sentir nos lugares descritos... é como se eu estivesse naquele lugar e naquele tempo". Um comentário da aluna A25 marcou esse nosso encontro: "podemos ser aquilo que queremos por meio da literatura". Nesse clima leve e sereno, despedimo-nos desse produtivo momento.

Segundo encontro do grupo "Diálogo Coletivo"

A leitura é muito mais do que decifrar palavras.

Uma arte que dá medo é a de ler um olhar, pois os olhos têm segredos difíceis de decifrar. (AZEVEDO, 1999, p. 9)

Nosso segundo encontro foi permeado por uma atmosfera nostálgica. Na própria sala da turma, em uma quarta-feira, 19 de setembro, no mesmo horário de costume, reunimo-nos e, juntos, pudemos voltar ao passado para relembrar quais foram as marcas que a família e a escola deixaram a respeito da formação em leitura. 
Como uma forma de deixá-los mais à vontade para se expressar, sugerimos que narrassem episódios de infância envolvendo a leitura. A ocasião favoreceu que cada aluno buscasse em suas memórias algo para compartilhar.

Uma das questões norteadoras desse encontro teve como objetivo averiguar a base familiar de incentivo à leitura e o resultado foi o seguinte:

GRÁFICO 2- A família e o incentivo à leitura

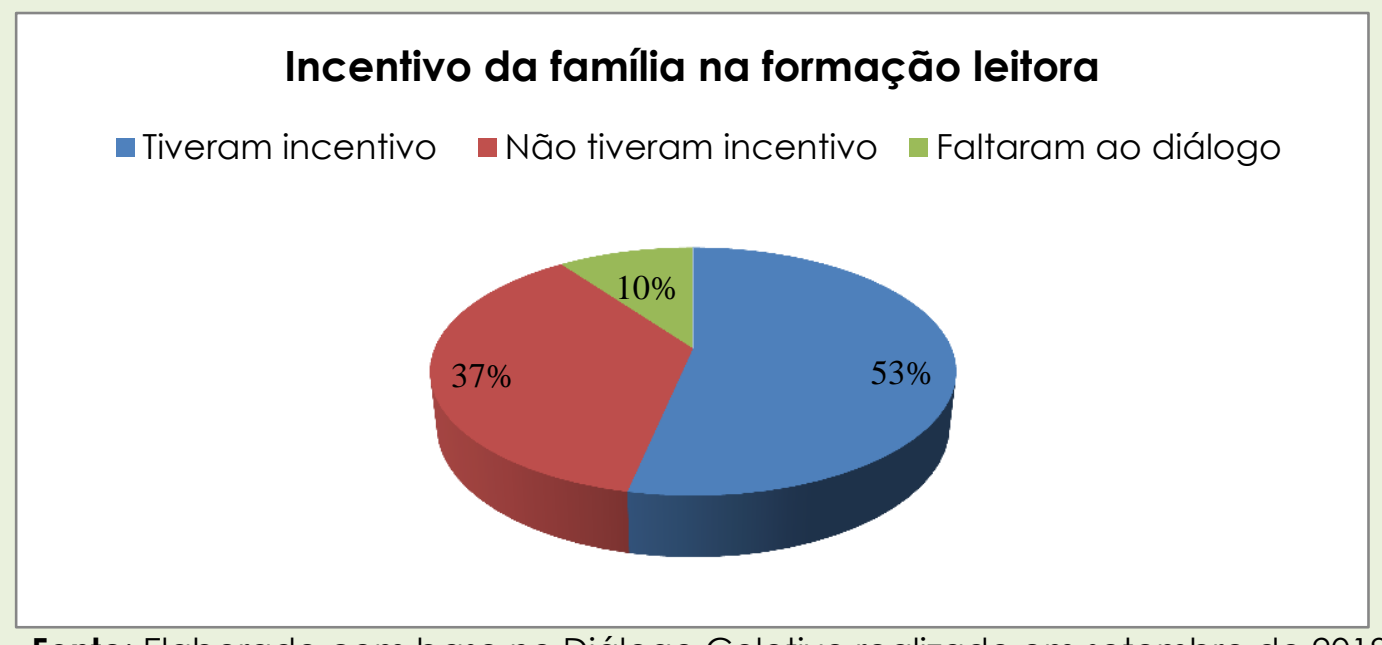

Fonte: Elaborado com base no Diálogo Coletivo realizado em setembro de 2018.

Dos vinte e sete alunos presentes, tivemos três ausências, cujos motivos já foram destacados e não caracterizam desistência na participação no grupo. Dezesseis afirmaram que receberam incentivo da família quando eram crianças e onze afirmaram que não. Os alunos que receberam influência da família partilharam com o grupo a forma como a família foi importante para o contato com a leitura; alguns deixaram as seguintes contribuições:

QUADRO 2- Depoimentos sobre influências para a leitura

\begin{tabular}{|l|l|}
\hline A36: "Minha mãe comprava coleções de livros desde quando era bem \\
pequenininha...sempre comprou...e fui gostando de ler". \\
\hline A6: & $\begin{array}{l}\text { "Meu pai é professor e sempre me incentivou a ler". } \\
\text { fazia...me dava mo minha mãe me recompensava pelas leituras que }\end{array}$ \\
\hline A25: & "Toda noite minha mãe lia para mim ... isso fez com que eu gostasse de \\
\hline
\end{tabular}




\begin{tabular}{|l|l|}
\hline & ler". \\
\hline A18: & $\begin{array}{l}\text { "Minha professora dava pra levar pra casa e minha mãe } \\
\text { acompanhava a leitura sempre". }\end{array}$ \\
\hline A7: & $\begin{array}{l}\text { "Quando já estava na 5a série pegava livros emprestados na biblioteca } \\
\text { da escola, quando chegava em casa minha mãe elogiava, com isso } \\
\text { até meu irmão menor começou a se interessar por livros". }\end{array}$ \\
\hline
\end{tabular}

Fonte: Criado com base em depoimentos dos alunos no grupo Diálogo Coletivo em setembro de 2018.

Dos dezesseis alunos que afirmaram ter recebido incentivo em casa, somente um não teria conseguido gostar de ler, conforme escreveu A22: "Minha mãe sempre mostrou que ler é importante, mas eu nunca consegui gostar... ela dizia quando eu era pequeno: tem que ler menino!". A forma como esse aluno se expressou deixa transparecer que, embora a mãe o exortasse a ler, não apresentava indícios de ser uma leitora. Esse caso difere dos outros em que os pais participavam de alguma forma dos momentos de leitura.

Esclarecemos que, embora as falas dos demais alunos não tenham sido transcritas na integra, eles compartilharam com o grupo que suas vivências de incentivo à leitura dentro de seus lares ocorreram do mesmo modo que os outros: compra de livros, leitura antes de dormir ou em outros momentos do dia e recompensas.

Despedimo-nos desse encontro com a certeza de que não somos páginas em branco, mas, por meio de nossas vivências e nossas bagagens, fazemo-nos diferentes e nos completamos.

Terceiro encontro do grupo "Diálogo Coletivo"

O leitor que mais admiro é aquele que não chegou até a presente linha. Neste momento já interrompeu a leitura e está continuando a viagem por conta própria.

(QUINTANA, 1973, p. 333)

O terceiro encontro, como combinado, ocorreu no dia 26 de setembro. O objetivo foi verificar alguns elementos que ajudassem a identificar o repertório literário dos alunos. Para isso, Ihes perguntamos o que 
costumavam ler e eles comentaram suas escolhas. Os resultados desse diálogo estão sistematizados a seguir:

QUADRO 3- Repertório literário dos alunos do $2^{\circ}$ ano A - Curso Técnico Integrado em Agropecuária, IFRO, Campus Colorado.

$$
\begin{aligned}
& \begin{array}{c|c}
\text { NÃO GOSTAM DE LER - } & \begin{array}{l}
\text { •Realizam a leitura somente do que é } \\
\text { "obrigatório" pela escola. }
\end{array}
\end{array} \\
& \text { CONSIDERAM-SE LEITORES } \\
& \text { - } 9 \text { ALUNOS } \\
& \text { - Leem de tudo um pouco. Gostam de ler. }
\end{aligned}
$$

Fonte: Diálogo Coletivo, 26/09/2018.

O que mostra o quadro? A primeira tarja indica o perfil de aluno que não realiza leitura por prazer, que lê apenas o que julga necessário para conseguir nota, ou seja, não enxerga benefícios na leitura, percebe-a como algo não prazeroso, chato e enfadonho. O aluno A21 comentou: "Se vale nota eu leio, se não, não vai acrescentar em nada". O aluno Al6 acrescenta: "Ler dá sono... não gosto".

A segunda tarja representa aqueles alunos que têm prazer em ler, percebem a leitura como uma oportunidade de desvendar o desconhecido, leem por que são curiosos, querem aprender coisas novas, não fazem distinção entre os textos, mas contemplam as diferenças. Por isso, acreditam que todas as leituras, independentemente do tipo de linguagem, só acrescentam conhecimentos. A aluna A25 comenta: "Gosto de ler de tudo um pouco, quando leio é como se eu estivesse em outros lugares, consigo entrar na cena que estou lendo." A aluna A36 complementa: "Leio do gibi ao clássico. Todas as leituras são interessantes, independente da linguagem".

A terceira tarja representa os alunos que selecionam suas leituras de acordo com o grau de dificuldade da linguagem do texto. Preferencialmente, optam por textos que apresentam um número maior de 
imagens e que sejam curtos. O fato de ter muitas páginas e não conter imagens são fatores decisivos para a escolha. O aluno A27afirma: "A primeira coisa que olho quando vou escolher um livro é o número de páginas, e depois se tem figuras".

Enfim, 15 alunos afirmaram que não têm interesse pela leitura e 15, de alguma forma, revelam que sim. Destes, 9 se consideram leitores assíduos e 6 estão em uma fase primária de leitura, não conseguem amadurecer: gostam de ler parcialmente, preferindo leituras que não exijam muita atenção. Textos que apresentam uma linguagem polissêmica, característica do texto literário, tornam-se alvo de repulsa, pois esses alunos não estão acostumados a refletir no e sobre o texto, a descobrir os mistérios das entrelinhas.

Depois de delinear o repertório de leitura dos alunos, consideramos necessário levantar as possíveis causas da rejeição dos alunos à leitura literária. Por isso, destinamos uma questão aos grupos de alunos da primeira e da terceira tarja, ou seja, aos que não gostam dos textos literários de forma alguma ou que os leem por obrigação mesmo, sem gostar. A questão foi: o que o distancia do texto literário?

Com base no que foi discutido, compusemos o seguinte quadro:

Quadro 4- Principais causas de rejeição dos alunos à leitura literária

\begin{tabular}{|l|l|l|}
\hline \multicolumn{1}{|c|}{ Problema } & \multicolumn{1}{|c|}{ Possíveis causas } & \multicolumn{1}{c|}{$\begin{array}{c}\text { Instrumento de coleta de } \\
\text { dados }\end{array}$} \\
\hline Falta de tempo & $\begin{array}{l}\text { Formato do curso; muitos } \\
\text { moram em outras cidades } \\
\text { ou na zona rural; os afazeres } \\
\text { extras dos alunos residentes. }\end{array}$ & $\begin{array}{l}\text { Diálogo Coletivo, diário de } \\
\text { bordo e análise } \\
\text { documental. }\end{array}$ \\
\hline $\begin{array}{l}\text { Dificuldades de } \\
\text { compreensão do } \\
\text { texto literário }\end{array}$ & $\begin{array}{l}\text { Falta de incentivo da família } \\
\text { e abordagem superficial da } \\
\text { literatura nos anos anteriores } \\
\text { ao ensino médio. }\end{array}$ & $\begin{array}{l}\text { Diálogo Coletivo, diário de } \\
\text { bordo e análise } \\
\text { documental. }\end{array}$ \\
\hline
\end{tabular}

Fonte: Elaborado com base nos dados levantados no Diálogo Coletivo e registrados no Diário de Bordo, em setembro de 2018.

A dificuldade de compreensão do texto literário cria um distanciamento entre os alunos e o texto, o que os leva a achá-lo "chato" e "desnecessário". Embora as possíveis causas dos dois maiores problemas 
também possam ser consideradas como problema, ativemo-nos à "falta de tempo" e às "dificuldades de compreensão do texto literário" para, assim, obter maior envolvimento dos alunos com o texto na perspectiva de ampliação de sua formação leitora.

Quarto encontro do grupo "Diálogo Coletivo"

No meio do caminho tinha uma pedra tinha uma pedra no meio do caminho

(ANDRADE, 2012, p. 287)

No dia 2 de outubro, na sala de aula da turma, às 14horas, realizamos o quarto encontro do grupo Diálogo Coletivo. Foi um momento de diálogos, risos e cochichos, o astral de todos e todas parecia muito bom e o encontro foi muito produtivo.

No encontro anterior, havíamos proposto duas questões. Neste, propusemos mais uma relativa ao direcionamento das leituras na disciplina de Literatura Brasileira.

Foi interessante que todos queriam falar ao mesmo tempo e tinham sugestões a dar. Nesse momento, retomamos a primeira parte do objetivo geral da pesquisa, que era investigar as principais causas da rejeição à leitura literária nessa turma. Como os alunos já haviam apontado problemas que, segundo eles, eram as causas de seu distanciamento da leitura, agora teriam a oportunidade de pensar "o que fazer", considerando a realidade atual e contextual. As discussões anteriores do grupo foram fundamentais para que identificássemos as principais causas; neste quarto encontro, eles deveriam pensar em estratégias.

Com base nas principais problemáticas levantadas, buscamos construir as estratégias para modificar a situação e, assim, chegamos à segunda parte do objetivo geral da pesquisa: intervir com práticas pedagógicas que levassem à formação do leitor literário. Com base em conversas e sugestões, chegamos ao seguinte quadro. 
QUADRO 5-Planejamento das ações

\begin{tabular}{|l|l|l|}
\hline \multicolumn{1}{|c|}{ Problemas } & \multicolumn{1}{|c|}{$\begin{array}{c}\text { Possíveis estratégias pensadas } \\
\text { coletivamente }\end{array}$} & \multicolumn{1}{c|}{ Planejamento } \\
\hline $\begin{array}{l}\text { Falta de } \\
\text { tempo }\end{array}$ & $\begin{array}{l}\text { Trabalhar textos curtos em sala como } \\
\text { contos e crônicas. }\end{array}$ & $\begin{array}{l}\text { Elaboração de sequências } \\
\text { didáticas. }\end{array}$ \\
\hline $\begin{array}{l}\text { Dificuldades } \\
\text { de } \\
\text { compreensão } \\
\text { do texto } \\
\text { literário }\end{array}$ & $\begin{array}{l}\text { Abordar os temas da Literatura de } \\
\text { maneira interdisciplinar com as } \\
\text { disciplinas de Arte e História. Utilizar o } \\
\text { lúdico por meio do teatro, da música } \\
\text { e outras formas de encantamento } \\
\text { que o texto literário permite. }\end{array}$ & $\begin{array}{l}\text { Elaboração de sequências } \\
\text { didáticas. }\end{array}$ \\
\hline
\end{tabular}

Fonte: Elaborado com base nas discussões no Diálogo Coletivo ocorridas em outubro de 2018.

Nesse momento, já era possível sentir que pesquisar e intervir é possível, mas não é fácil, pois exige mudanças de atitudes. Percebemos a pesquisaação como emancipatória, pois o grupo assumiu coletivamente a responsabilidade de transformação da prática.

O valor social do diálogo como prática educativa é exposto por Pereira (1998, p. 177): "O diálogo entre professor e aluno constitui princípio de procedimento que leva ao conhecimento crítico do ponto de vista educativo e estabelece uma relação forte com o processo de levar a pensar, ao invés de apenas se preocupar com o resultado do processo.".

É notório que o aprendizado se faz na vivência, no dia a dia e que, nesse processo, o professor compartilha saberes e também recebe. Essa troca de conhecimento dá significado ao contexto e também favorece que, em meio aos conflitos, ele desvende novos caminhos. O resultado é um professor mais preparado para enfrentar os desafios e com um entendimento maior dos motivos que o inserem na profissão.

Para minimizar os problemas evidenciados, buscamos (re) descobrir caminhos de ensino de Literatura, utilizando a sequência didática, que contempla os objetivos do trabalho colaborativo de forma sistemática e planejada. (DOLZ; NOVERRAZ; SCHNEUWLY, 2004).

No próximo item, destinado ao fruto da pesquisa, ao produto educacional, vamos analisar as quatro sequências didáticas produzidas com 
base nos principais problemas evidenciados pela turma participante da pesquisa. O pressuposto era de que tais sequências poderiam se constituir em uma prática pedagógica diferenciada, capaz de proporcionar novos rumos para o ensino de literatura em realidades similares.

\section{Caminhos percorridos na construção das sequências didáticas}

As quatro sequências didáticas atendem ao objetivo geral desta pesquisa, qual seja, o de intervir com práticas pedagógicas que levassem à formação do leitor literário. Por isso, caracterizamos tais sequências como um produto educacional3.

$\mathrm{Na}$ investigação sobre o repertório literário dos alunos e as possíveis causas da rejeição à leitura literária, selecionamos dois dos maiores problemas e depois discutimos as estratégias para minimizá-los. A seguir, vamos expor as estratégias adotadas para cada problema.

QUADRO 6-Principais problemas e possíveis estratégias

\begin{tabular}{|l|l|}
\hline \multicolumn{1}{|c|}{ Problemas } & \multicolumn{1}{c|}{ Estratégias } \\
\hline 1. Falta de tempo & $\begin{array}{l}\text { Trabalhar textos curtos em sala como contos e } \\
\text { crônicas. }\end{array}$ \\
\hline $\begin{array}{l}\text { 2. Dificuldades de } \\
\text { compreensão do texto }\end{array}$ & $\begin{array}{l}\text { Abordar os temas da Literatura de maneira } \\
\text { interdisciplinar com as disciplinas de Arte e História. } \\
\text { Utilizar o lúdico por meio do teatro, da música e de } \\
\text { outras formas de encantamento que o texto } \\
\text { literário permite. }\end{array}$ \\
\hline
\end{tabular}

Fonte: Elaborado a partir dos dados levantados no Diálogo Coletivo e registrado no Diário de Bordo, em setembro de 2018.

As quatro sequências didáticas, correspondentes a essas estratégias, foram embasadas na teoria da estética da recepção (JAUSS, 1979) e na proposta de ensino de Literatura que busca intervir nos problemas (COSSON, 2006).

3Produzido com base na dissertação intitulada "Os desafios da leitura literária no ensino médio: (re) descobrindo caminhos", cuja defesa foi um dos requisitos para obtenção do título de Mestre em Educação Escolar, no Programa de Pós-Graduação em Educação Escolar - Mestrado e Doutorado Profissional - Universidade Federal de Rondônia, Porto Velho. 
Assim, durante o bimestre, dedicamo-nos ao desenvolvimento das seguintes de sequência didáticas: Revivendo os Clássicos da Literatura; Vamos ler crônicas?; Círculos de leitura no contexto escolar e Hora da poesia.

\section{Alguns apontamentos sobre o desenvolvimento das sequências didáticas}

"[...] Para a leitura se efetivar, deve preencher uma lacuna em nossa vida, precisa vir ao encontro de uma necessidade, de um desejo de expressão sensorial, emocional ou racional, de uma vontade de conhecer mais". (MARTINS, 1986, p. 82)

Na realização das sequências, foi possível contemplar todas as etapas de discussão e os alunos leitores puderam fazer suas inferências a respeito das leituras e privilegiar as associações que cada um fez com base em sua bagagem de vida, interagindo com a obra em um dado contexto. Os alunos puderam também experimentar a literatura como "uma experiência única de escrever e ler o mundo e a nós mesmos" (COSSON, 2006, p. 120). O caráter humanizador da literatura (CANDIDO, 2011) também se fez presente em todas as sequências desenvolvidas.

Nas intervenções, levamos em consideração a diversidade dos alunos e os problemas por eles identificados, de forma que se sentissem estimulados na realização das atividades.

A avaliação das sequências didáticas ocorreu por meio da observação do comportamento, da análise da interação entre os alunos nas atividades, de perguntas em rodas de conversa durante a execução das etapas e também de produções orais e escritas. Além disso, disponibilizamos uma caixinha para depósito das devolutivas a respeito da forma de encaminhamento das atividades e também para sugestões.

Por meio das avaliações descritas, foi possível levantar os pontos positivos e/ou negativos de cada sequência, levando cada aluno leitor a refletir sobre seu processo. 
As principais considerações a respeito de cada sequência didática realizada, segundo a percepção dos alunos com a mediação da professora, foram as seguintes:

QUADRO 7- Avaliação das sequências didáticas

\section{Revivendo os Clássicos da Literatura.}

Foram identificados aspectos positivos na proposta de abordagem interdisciplinar. O professor de História pôde contextualizar os aspectos histórico-sociais de cada obra estudada, associando sua importância no passado e no presente. A professora de Arte oportunizou um momento para que cada obra pudesse ser (re)contada de acordo com as habilidades artísticas dos alunos. Todos participaram de cada etapa proposta, demonstrando que estavam motivados para a apresentação artística e também para a confecção dos folders, pois queriam fazer "bonito". No momento da apresentação artística, sentiram-se à vontade para representar a obra lida por meio do teatro, da música, de pinturas e de gravações de vídeos. Nas discussões, conseguiram relacionar fatos do passado com a realidade presente; por exemplo, a leitura de "A escrava Isaura" foi associada com a questão de muitas mulheres ainda serem vítimas de certos tipos de "escravidão". Essa etapa foi muito produtiva. Os alunos consideraram que todas as discussões sobre o contexto histórico da época a que pertenciam as obras lidas foram válidas, pois ajudaram a preencher muitas lacunas do texto, inclusive a respeito do comportamento de algumas personagens. Todos afirmaram que a abordagem interdisciplinar prendeu a atenção para o desenvolvimento das atividades. O aluno A30 relatou: "todas as disciplinas poderiam fazer assim". Porém, o desenvolvimento da sequência não assegurou que todos lessem a obra na integra; assim, para levá-los a utilizar a sensibilidade artística e dar forma às suas expressões, foi preciso realizar a leitura de fragmentos.

\section{Vamos ler crônicas?}

Os alunos participaram ativamente de todas as etapas propostas. Foi visível que se empenharam na leitura, riscando palavras desconhecidas, trocando ideias com os colegas e relendo o texto. Participaram ativamente das discussões e também na produção escrita. No momento de compartilhar uma passagem da crônica que chamou sua atenção, A15 perguntou se poderia fazer em voz alta a leitura de "A última Crônica" de Fernando Sabino para a sala e o fez, mas, quando chegou ao episódio que descreve a felicidade da criança e de sua família ao comemorar seu aniversário com uma fatia de bolo simples, começou a chorar muito e não conseguiu prosseguir com a leitura. Afirmando que "somos ingratos e reclamamos por pouca coisa", pôde compartilhar com a turma que o texto a tocara profundamente. Assim, os alunos puderam perceber que cada um recebe o texto literário conforme sua individualidade, é tocado por ele de uma determinada maneira e que a leitura desperta sentimentos e emoções que poderiam estar adormecidos. Na caixinha da devolutiva das atividades, os alunos relataram que a leitura de textos em sala é mais produtiva porque faz com que todos leiam, enquanto em casa é muito difícil. Relataram também que o compartilhamento das impressões sobre o texto com os colegas melhora o entendimento. Todos os alunos realizaram a produção escrita com empenho. Não foi destacado nenhum ponto negativo na execução dessa sequência. 


\section{Círculos de leitura no contexto escolar}

A obra lida e discutida no círculo foi "O caçador de pipas" de Khaled Hosseini. A maior parte dos alunos realizou na íntegra a leitura da obra, mas percebemos que alguns não a leram porque acharam extensa demais, embora tenham se interessado por sua apresentação cultural. Ficou visível na discussão que os alunos que não leram somente assistiram ao filme do mesmo título. De modo geral, a temática abordada na obra e o fato de se tratar de uma literatura estrangeira ajudaram consideravelmente na criação de um elo entre leitores e obra. Nos círculos de discussão, os alunos leitores relacionaram passagens da obra com episódios de suas vidas e, nas apresentações artísticas, tendo optado pela paródia, puderam estreitar o laço de amizade entre si, resolvendo até mesmo alguns conflitos de convivência. As paródias foram encenadas e todos os alunos expressaram artisticamente o texto literário. Em sua maioria, eles avaliaram positivamente essa sequência, mas apontaram como fator negativo que alguns não tivessem lido. Alguns pediram para que fossem escolhidas obras com menos páginas. Também sugeriram que em todos os encontros do círculo fosse oferecido lanche e que outras turmas pudessem participar.

\section{Hora da poesia}

Ficou visível com essa sequência que alguns alunos apresentaram maior desinibição para recitar o poema, ao passo que outros se mostraram tímidos, relatando que não se sentiam seguros quanto à entonação da leitura. Como a dificuldade foi diagnosticada no início, pudemos acompanhá-la e minimizá-la com a previsão de um tempo maior para a leitura. A fase das atividades em que todos se manifestaram sem divisão foi a das discussões: sem distinção os alunos compartilharam seu entendimento de cada indagação suscitada. A23 associou o poema à música "Tocando em frente", de Almir Sater, porque esta está em primeira pessoa e denota um estado de espírito. Todos falaram e perceberam nas próprias falas, o caráter plurissignificativo do texto e também que o poema se fez poesia à medida que despertou sentimentos diferentes e os reportou para outro contexto. Os vários tipos de leitura apresentados foram produtivos, pois tanto ajudaram na depreensão de sentidos quanto na exploração dos traços sonoros do texto. Um ponto negativo indicado pelos alunos e também percebido pela professora foi a produção escrita, o texto autobiográfico. Muitos alunos não se sentiram à vontade para desenvolvê-lo, mesmo sabendo que era o eu-lírico que se manifestaria. Sentiram dificuldade para separar o próprio ser do "ser poético" em razão do perfil da turma: como muitos vivenciaram conflitos emocionais não se sentiram à vontade para realizar essa etapa. Depois de toda a execução da sequência e do estudo do perfil da turma, percebemos que essa etapa escrita poderia ser substituída pela realização de acrósticos ou pela releitura do poema por meio da pintura.

Fonte: Dados coletados durante a execução das sequências didáticas, setembro e outubro de 2018.

Apesar de alguns pontos negativos, conforme destacamos no quadro, todas as sequências cumpriram o objetivo maior da pesquisa, proporcionando autonomia e papel de destaque ao leitor. Em cada sequência, foi respeitada a forma como o aluno leitor recebeu o texto, de 
forma que todos puderam comprovar questionar ou modificar suas expectativas (JAUSS, 1979). Notamos que o leitor desempenhou seu papel, que "se realiza, histórica e individualmente, de acordo com as vivências e a compreensão previamente constituída que os leitores introduzem na leitura" (ISER, 1979, p. 78).

Na seleção de todos os textos a serem trabalhados com os alunos, houve a preocupação de, em algum momento, promover a abordagem de algo que estivesse relacionado ao seu cotidiano. Assim, o repertório de cada aluno entrelaçado ao texto serviu de estímulo para que todos atuassem ativamente na leitura (JAUSS, 1994).

No momento da recepção do texto, os leitores tiveram a oportunidade de interpretar e inferir as questões propostas, tomando a liberdade de responder de acordo com sua vivência e com a expectativa da voz ou vozes presentes no texto. Todos esses fatores foram percebidos como motivacionais, além do crescimento mútuo e do conhecimento gerado a partir dos diálogos levantados.

Assim, conforme Zabala (1998, p.59), analisar/avaliar é importante, pois significa "reconhecer as possibilidades e as carências de cada unidade, com o fim de que nos permita compreender outras propostas e reconhecer em cada momento, aquelas sequência que se adaptam mais às necessidades educacionais de nossos alunos".

\section{CONSIDERAÇÕES FINAIS}

"Lê-se para entender o mundo, para viver melhor. Em nossa cultura, quanto mais abrangente a concepção de mundo e de vida, mais intensamente se lê, numa espiral quase sem fim, que pode e deve começar na escola, mas não pode (nem costuma) encerrar-se nela". (LAJOLO, 2004, p.7).

Na presente pesquisa, buscamos investigar as principais causas da falta de interesse pela leitura literária por parte dos alunos do segundo ano do ensino médio do IFRO campus Colorado do Oeste/RO. A falta de tempo 
e a dificuldade de compreensão dos textos literários foram apontados como os dois maiores fatores de distanciamento entre estudantes e literatura.

A formação do grupo Diálogo Coletivo foi fundamental para o levantamento dos dados, proporcionando um espaço para a reflexão e para a transformação da realidade. Constatamos que a falta de tempo decorre do próprio caráter do curso, qual seja, de um curso integral, em uma escola situada na zona rural. O segundo fator de distanciamento e de dificuldade para a compreensão dos textos relaciona-se à falta de incentivo familiar, especialmente nos anos iniciais. O resultado é que 15 dos alunos participantes não gostam de ler; os outros 15 se dividem entre os que se consideram leitores assíduos e os que até gostam de fazer determinadas leituras, porém, como têm dificuldade na compreensão, acabam escolhendo leituras com palavras simples, mais ilustrações e menor número de páginas.

Por ser tratar de uma pesquisa-ação, além da investigação inicial, buscamos meios para minimizar os problemas levantados, promovendo práticas pedagógicas que levassem à formação do leitor literário. Para tanto, planejamos, em conjunto com os alunos participantes do grupo Diálogo Coletivo, quatro sequências didáticas a ser executadas e avaliadas. Tais atividades foram instituídas como produto educacional e organizadas em formato de caderno.

Para minimizar o primeiro problema os alunos sugeriram valorizar mais a leitura em sala de aula, utilizando textos curtos e garantindo assim que todos efetuassem a leitura. Já o segundo, foi considerado como um problema mais complexo, que impede a visualização de um resultado rápido: o problema da dificuldade de compreensão do texto literário é oriundo de fortes negligências com a literatura ainda na formação basilar do aluno leitor. Assim, a estratégia foi envolvê-los em atividades que primeiramente despertassem a vontade de querer participar, que os motivasse de alguma maneira. Os alunos sugeriram que fossem realizadas atividades descontraídas e animadas. Dessa forma, em uma das sequências 
didáticas, trabalhamos com uma abordagem interdisciplinar, agregando teatro, música, paródia, e outras expressões artísticas.

As sequências didáticas proporcionaram um maior planejamento das atividades, pois, à medida que cada detalhe das etapas foi sendo descrito, o professor pôde visualizar a situação como se fosse uma cena. Outro fator importante é que tais etapas foram construídas com base em um objetivo, cada ação tinha uma meta pré-estabelecida. A organização prévia levou à constante avaliação dos meios utilizados: se eles contribuíam ou não para uma aprendizagem.

Assim, por meio das discussões no grupo Diálogo Coletivo e das reflexões acerca de diversas situações da prática docente, fizemos uma proposta de intervenção no problema, uma alternativa para minimizar o distanciamento apresentado pelos alunos em relação aos textos literários. Percebemos que, quando os alunos também se colocam na posição de pesquisadores, envolvem-se mais nas tomadas de decisão e na conscientização sobre as mudanças, já que é preciso de um envolvimento mútuo para a transformação de uma determinada situação.

Todas as quatro sequências, cada qual à sua maneira, possibilitaram uma aproximação maior entre alunos leitores e texto literário. De uma perspectiva teórica e prática, percebemos que as etapas que as constituíram podem levar à formação do leitor literário. Quanto a afirmar em que medida a intervenção realizada contribuiu para a formação do leitor literário da turma do segundo ano do curso Técnico em Agropecuária do IFRO - campus Colorado do Oeste/RO, é preciso considerar que os resultados deste trabalho são gradativos. $O$ primeiro passo já foi dado nesse processo de formação, que deve se aperfeiçoar à medida que cada aluno leitor se abrir para novas experiências de leitura. 


\section{REFERÊNCIAS}

ABDALLA, M. de F. B. A Pesquisa-ação como Instrumento de Análise e Avaliação da Prática Docente.Ensaio: aval. pol. públ. Educ., Rio de Janeiro, v. 13, n.48, p. 383-400, jul./set. 2005.

ALARCÃO, I. Professor-investigador: Que sentido? Que formação? In: CAMPOS, B. P. (org.). Formação profissional de professores no ensino superior. v. 1. Porto: Porto Editora, 2001. p. 21-31.

ANDRADE, C. D. de. Antologia poética. Organizada pelo autor. São Paulo: Companhia das Letras, 2012.

AZEVEDO, R. Dezenove poemas desengonçados. São Paulo: Ática, 1999.

BAKHTIN, M. Estética da criação verbal. 4. ed. São Paulo: Martins Fonseca, 1988.

BARBIER, R. A Pesquisa-ação. Brasília: Líber Livro Editora, 2004.

CANDIDO, A. O direito à literatura. In:CANDIDO, A. Vários escritos. 5. ed. Rio de Janeiro: Ouro sobre Azul, 2011 [1998]. p. 171-193.

COSSON, R. Letramento Literário: teoria e prática. São Paulo: Contexto, 2006.

CONTRERAS, J. A autonomia de professores. São Paulo: Cortez, 2002.

DOLZ J.; NOVERRAZ, M.; SCHNEUWLY, B. Sequências didáticas para o oral e escrita: apresentação de um procedimento. In: DOLZ J.; NOVERRAZ, M.; SCHNEUWLY, B. Gêneros orais e escritos na escola. Tradução e organizaçãoRoxane Rojo e Glaís Sales Cordeiro. Campinas: Mercado de Letras, 2004. p. 95-128.

ELLIOTT, J. Recolocando a pesquisa-ação em seu lugar original e próprio. In: GERALDI, C.; FIORENTINI, D.; PEREIRA, E. (org.). Cartografias do trabalho docente. Campinas: Mercado das Letras/ALB, 1998. p. 137-152.

FIGUEIRA, L. R. do C. A educação literária sob duas perspectivas: objetivo comum. Revista Exitus, Santarém/PA, Vol. 8, No 2, p. 300-328, Maio/Ago, 2018. Disponível em:

http://www.ufopa.edu.br/portaldeperiodicos/index.php/revistaexitus/article/ view/539/350. Acesso em: 05 jan. 2020.

FONSECA, L. A.; PACÍFICO, J. M.; NICHIO, E. R.; SOUZA, A. M. de L. A literatura de Clarice Lispector como instrumento de subjetivação em aulas de Língua Portuguesa. EDUCA - Revista Multidisciplinar em Educação, Porto Velho, v. 6, n. 13, p. 114-127, jan/mar, 2019. Disponível em: 
http://www.periodicos.unir.br/index.php/EDUCA/article/view/4127/2721.

Acesso em: 10 jun. 2019.

FREIRE, P. Ação cultural para a liberdade: e outros escritos. 12. ed. São Paulo: Paz e Terra, 2007.

FREIRE, P. Pedagogia da Autonomia: saberes necessários à prática educativa. Rio de Janeiro: Paz e Terra, 1997.

FREIRE, P. Educação e Mudança. 12. ed. Rio de Janeiro: Paz e Terra, 1979.

GADOTTI, M. (org.). Paulo Freire: uma bibliografia. São Paulo: Cortez, Instituto Paulo Freire; Brasília, DF: UNESCO, 1996.

GATTI, B. A. Grupo focal na pesquisa em Ciências sociais e humanas. Brasília: Líber Livro, 2005.

ISER, W. O Jogo do texto. In: LIMA, L. C. A Literatura e o leitor: textos de estéticas da recepção. Rio de Janeiro: Paz e Terra, 1979. p. 105-1 18.

JAUSS, H. R. A estética da recepção: colocações gerais. In: LIMA, L. C. A Literatura e o leitor: textos de estéticas da recepção. Rio de Janeiro: Paz e Terra, 1979.

JAUSS, H. R. A história da literatura como provocação à teoria literária. São Paulo: Ática, 1994.

LAJOLO, M. Do mundo da leitura para a leitura do mundo. 6. ed. São Paulo: Editora Ática, 2004.

LARROSA, J. Notas sobre a experiência e o saber da experiência. Notas sobre a experiência e o saber de experiência. Revista Brasileira de Educação, São Paulo: Associação Nacional de pós-graduação e Pesquisa em Educação, n. 19, p. 20-28, jan-abril, 2002. Disponível em:

http://www.scielo.br/pdf/rbedu/n19/n19a02.pdf. Acesso em: 02 abr. 2018.

LEMINSKI, P. O ex-estranho. São Paulo: lluminuras, 1996.

LUDKE, M.; ANDRÉ, M. E. D. A. Pesquisa em educação: abordagens qualitativas. 2. ed. Rio de Janeiro: E.p.u., 2017.

LUNA, S. V. de. Planejamento de pesquisa: uma introdução. São Paulo: Ed. Educ., 2002.

MARTINS, M. H.O que é leitura. 8. ed. São Paulo: Brasiliense, 1986. 
OLIVEIRA, A. dos S.; VELANGA, C. T.; PACífICO, J. M. Saberes necessários ao professor mediador da leitura literária infantil. Revista Exitus, Santarém, PA Vol. $6 N^{\circ} 1$ p. $160-174$ Jan./Jun., 2016. Disponível em:

http://www.ufopa.edu.br/portaldeperiodicos/index.php/revistaexitus/article/ view/46/46. Acesso em: 10 jan. 2019.

PEREIRA, E. M. de A. Professor como Pesquisador: o enfoque da pesquisaação na prática docente. In: GERALDI, C. M. G.; FIORENTINI, D.; PEREIRA, E. M. de A. (org.). Cartografias do trabalho docente: professor (a)-pesquisador (a). Campinas: Mercado das Letras, 1998.

RODRIGUES, C. R.; MATTIA, J. L. de; SILVA, R. A. da. Trânsito: crenças, construções e desconstruções para a educação. EDUCA - Revista Multidisciplinar em Educação, Porto Velho, v.4, n.7, p. 24-44, jan/abr, 2017. Disponível em:

http://www.periodicos.unir.br/index.php/EDUCA/article/view/1808/1895. Acesso em: 15 abr. 2018.

STENHOUSE, L. Investigación y desarrollo del curriculum. Madrid: Morata, 1984.

ZABALA, A. A prática educativa: como ensinar. Porto Alegre: Artmed, 1998.

Recebido em: 15 de março de 2020 Aprovado em: 16 de abril de 2020 Publicado em: 15 de maio de 2020

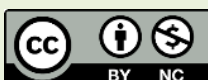

